\title{
The Influence of High Temperature Exposure on the Wear of Selected HVOF Sprayed Coatings
}

\author{
HOUDKOVÁ Šárka ${ }^{1, a}$, SMAZALOVÁ Eva ${ }^{2, b}$ \\ ${ }^{1}$ University of West Bohemia, Univerzitní 8 , Plzeň, Czech Republic \\ ${ }^{2}$ University of West Bohemia, Univerzitní 8, Plzeň, Czech Republic \\ ahoudov@ntc.zcu.cz, bsmazal@ntc.zcu.cz
}

Keywords: HVOF, coating, high temperature, wear, indentation fracture toughness

\begin{abstract}
The influence of high temperature exposure on the mechanical and wear properties of selected HVOF sprayed $\mathrm{CrC}$ and $\mathrm{No} / \mathrm{Co}$ - based alloy coatings were tested. Comparison of assprayed and $600^{\circ} \mathrm{C} / 116 \mathrm{~h}$ annealed coatings' microhardness, cohesive strength, abrasive and adhesive wear resistance showed that the Co-based Stellite 6 coating's wear properties were deteriorated by heat exposure despite of the increase of its hardness and cohesive strength. The heat exposure was found to be beneficial for both mechanical and wear properties of NiCrBSi selffluxing coating. On the contrary, mechanical properties of $\mathrm{Cr}_{3} \mathrm{C}_{2}-\mathrm{NiCr}$ coating slightly decreased, while its wear resistance slightly increased as a result of high temperature exposure.
\end{abstract}

\section{Introduction}

The HVOF (High Velocity Oxygen Fuel) sprayed coatings are applied on parts surface namely for increasing the wear resistance and enhancing their lifetime. In high temperature applications, not only the coatings' high wear resistance, but also the resistance against the oxidation and stability of their functional properties is necessary.

Such a combination can be found at the $\mathrm{CrC}$ and $\mathrm{Ni} / \mathrm{Co}$ based materials with high content of $\mathrm{Cr}$, resisting to oxidation. Their high hardness makes them also suitable for wear prevention. But while their wear resistance in as-sprayed state is known and was reported many times [1], less is known concerning their behavior under working condition or after the heat exposure. Different microstructural changes, not only oxidation, can take place in the vicinity of high temperature that can further influence their mechanical and tribological properties. In our previous work [2], microstructural changes of $\mathrm{CrC}$ and $\mathrm{Co} / \mathrm{Ni}$ based HVOF coatings were described by XRD analyses and stability of hardness values were reported. In this paper, the attention was paid to the abrasion and adhesion wear resistance of as-sprayed and annealed coatings. Not only hardness but also coatings' cohesion strength was measured to find the relation between microstructural changes, mechanical properties and wear resistance.

\section{Experimental}

Feedstock material. Three kinds of feedstock powders were evaluated: (i) Co-based alloy (denoted as Stellite 6) FST 484.33 with nominal composition $28 \% \mathrm{Cr}$; 5\%W; 1.2\%C; 1\% balance, gas atomized, $(20-53 \mu \mathrm{m})$; (ii) Ni-based alloy (denoted as NiCrBSi) FST 771.33 with nominal composition $15 \% \mathrm{Cr} ; 4 \% \mathrm{Fe} ; 4.25 \% \mathrm{Si} ; 3 \% \mathrm{~B} ; 0.7 \% \mathrm{C}$; Ni balance, gas atomized, $(20-53 \mu \mathrm{m})$ size range size range and (iii) hardmetal FST M-588.074 - $\mathrm{Cr}_{3} \mathrm{C}_{2}-25 \% \mathrm{NiCr}$, agglomerated and sintered, $(15-45 \mu \mathrm{m})$ size range.

Spraying. The JP 5000 gun was used for thermal spraying of all three coatings onto grid blasted $\left(\mathrm{Al}_{2} \mathrm{O}_{3}, 0.8-1 \mathrm{~mm}\right.$ grain size) carbon steel substrates. The spraying parameters were previously optimized and are reported elsewhere [2]. The thickness of sprayed coatings varied between 400 and $500 \mu \mathrm{m}$. 
Heat exposure. The uncoated parts of steel samples were protected against oxidation by oxidation protective paint CONDURSAL Z 1100. The samples were than annealed in air atmosphere in muffle furnace at $600^{\circ} \mathrm{C}$ for 116 hours and then cooled in air.

Microstructure. The experimental details and results of microstructure evaluation were reported previously [2].

Mechanical properties. The microhardness HV 0.3 was measured in the middle of the coatings cross section. The average was determined from at least 8 measurements. The cohesion strength was measured by Vickers indentor, using $150 \mathrm{~N}$ load. At least 7 measurements were done for each coating, in the middle of coating's cross section. The simple Lawn and Swain equitation [3] were used to calculate the resistance against cracks' spreading:

$$
K_{I c}=0.001 \frac{L}{a \cdot \sqrt{c}}
$$

where $L[\mathrm{~N}]$ is the load, $a[\mathrm{~mm}]$ is the half of the Vickers diagonal and $c[\mathrm{~m}]$ is the sum of the half of the Vickers diagonal and the length of the crack, originated from Vickers indent's corner.

Wear properties. The abrasive wear resistance was evaluated by Dry Sand Rubber Wheel Test according to ASTM G65. Testing parameters were as follows: $22 \mathrm{~N}$ Load; $\mathrm{Al}_{2} \mathrm{O}_{3}$ abrasive media; AG 29 rubber counterpart; $718 \mathrm{~m}$ total abrasive distance. The samples were weighted after each 143 $\mathrm{m}$ and the weight loss were converted to volume loss using the density values, determined experimentally using the Archimedes' low. The surface of both as-sprayed and annealed coatings was left in as-sprayed state. The surface roughness is worn-out during first abrasive cycle, and is not included in the wear rate calculation. The sliding wear resistance was evaluated by Ball-on-Flat test, according to ASTM G133. Testing parameters were as follows: $25 \mathrm{~N}$ Load; steel100Cr6, $6 \mathrm{~mm}$ diameter ball counterpart; $5 \mathrm{~Hz}$ oscillating frequency; $10 \mathrm{~mm}$ stroke length; $1000 \mathrm{~s}$ testing time. For each coating, three different measurements were performed. The wear tracks profiles were measured by profilometer KLA-Tencor P-6 Profiler, at three different places, and the wear volume was calculated. Prior to sliding wear tests, the surface of the coating was grinded and polished to the $0.04 \pm 0.02 \mathrm{Ra}$ value.

Both the abrasive and adhesive wear was characterized by the coefficient of wear $\mathrm{K}\left[\mathrm{mm}^{3} / \mathrm{Nm}\right]$, calculated from the coating volume loss, used load and the abrasive or sliding distance:

$$
K=\frac{V}{L . S}
$$

where $\mathrm{V}$ is the volume loss $\left[\mathrm{mm}^{3}\right], \mathrm{L}[\mathrm{N}]$ is the load and $\mathrm{s}[\mathrm{m}]$ is the abrasive or sliding distance.

\section{Results}

The hardness and brittleness are the two properties, believed to be the most important for wear resistance of materials [4]. In this work, the influence of high temperature exposure on the mechanical properties of evaluated coatings was studied, comparing the microhardness and resistance against spreading of cracks, originating from the high-loaded Vickers indents' corners of as-sprayed and annealed coatings. No significant changes of measured microhardness were observed as a result of annealing of the coatings. With respect to the scatter, the values were similar for assprayed and annealed coating (Fig.1a). The least hard was Stellite 6 coating, followed by harder $\mathrm{NiCrBSi}$ coating and the hardest $\mathrm{Cr}_{3} \mathrm{C}_{2}-\mathrm{NiCr}$ coating. The influence of annealing temperature on hardness was studied in more detail in the previous work [2]. The coatings' cohesive strength seems to be more influenced by the high temperature exposure. The parameter $\mathrm{K}_{\mathrm{Ic}}$ represents the resistance of the material against cracks' spreading. In the case of alloy-based anisotropic thermally sprayed coating the cracks are spreading usually along the splat boundaries (Fig. 2). So, the resistance against the cracks' spreading represents in fact rather the coatings' cohesive strength than the fracture toughness of the coating material itself. The temperature exposure caused an increase of 
intersplat cohesive strength of both alloy coatings, while the cohesion of $\mathrm{Cr}_{3} \mathrm{C}_{2}-\mathrm{NiCr}$ coating decreased significantly (Fig. 1b.).
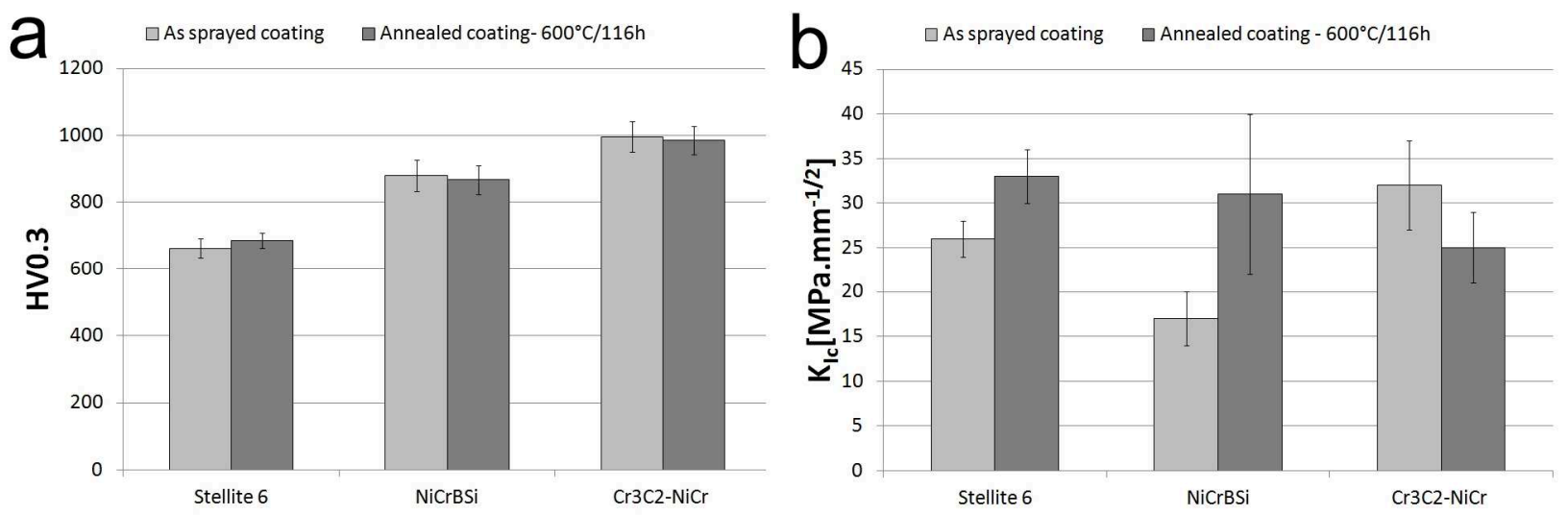

Fig.1.: Comparison of measured mechanical properties of as-sprayed and annealed coatings a) microhardness HV0.3; b) cohesion strength
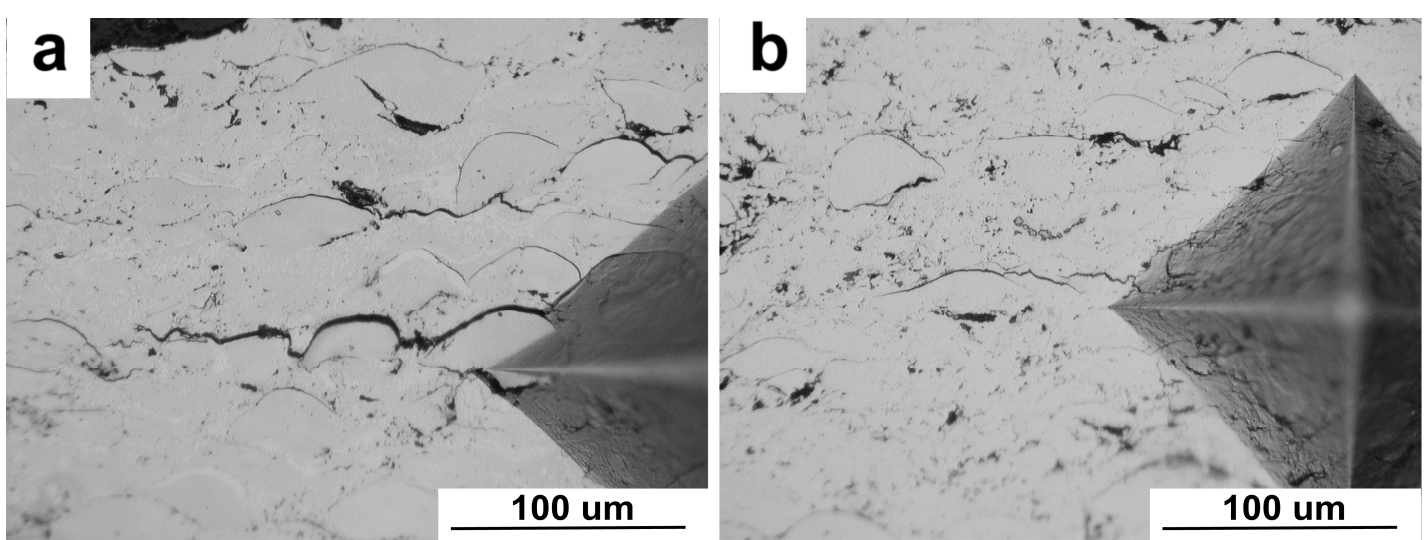

Fig.2. Spreading of the crack, initiated from the Vickers indents corner a) as-sprayed Stellite 6 coating; b) annealed Stellite 6 coating

The abrasive and adhesive wear resistance of evaluated coatings in as-sprayed and annealed state are summarised in the graphs in the Figure 3. The abrasive wear of two alloy coating in as-sprayed state is comparable, even if Stellite 6 coating is slightly more wear resistant in the as-sprayed state. Annealed, the coatings showed opposite tendency. The Stellite 6 coating's wear resistance significantly decreased, while increase was recorded for NiCrBSi coating. In the adhesive wear test, the NiCrBSi coating is much better compare to Stellite 6 coating, and its resistance is even increased by high temperature exposition. The wear of hardmetal $\mathrm{Cr}_{3} \mathrm{C}_{2}-\mathrm{NiCr}$ is the lowest and only little influenced by the by high temperature exposure.
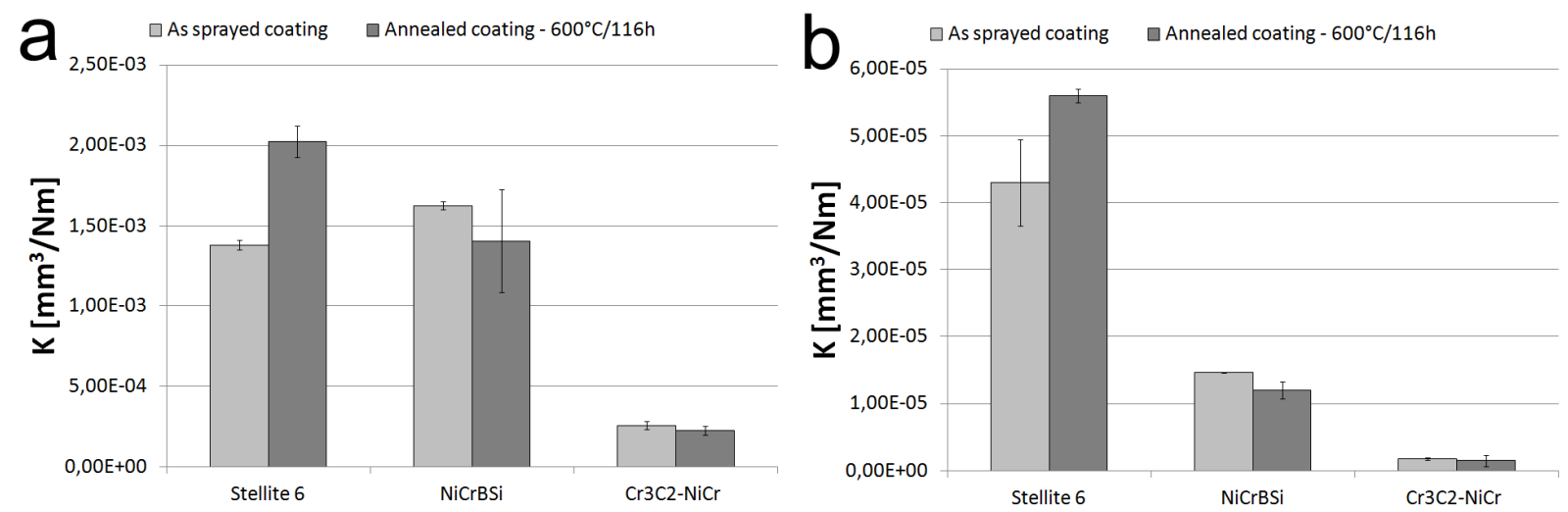

Fig.3 Wear Coefficient K [mm³ $/ \mathrm{Nm}]$, measured by a) ASTM G-65 test and b) ASTM G-133 test 
The overall measured wear resistance is in agreement with the microhardness results. The relatively soft Stellite 6 coating is followed by harder NiCrBSi coating and the hardest $\mathrm{Cr}_{3} \mathrm{C}_{2}-\mathrm{NiCr}$ coating. The resistance against crack's spreading itself did not show any relationship to the measured wear.

The explanation of influence of high temperature exposure is even less obvious. Even if the microhardness was almost unchanged and the cohesion strength of the alloy coatings increases by annealing, the positive effect was recorded only for NiCrBSi coating. On the other hand, the $\mathrm{Cr}_{3} \mathrm{C}_{2-}$ $\mathrm{NiCr}$ coating, with lower microhardness and worse cohesion strength seems to have even better wear resistance. Considering the microstructure changes, reported in [2], the explanation can be suggested. The deterioration of Stellite 6 wear properties can be related to the change its crystal structure. The XRD measurement showed the increase of hcp crystal structure from $30 \mathrm{wt} \%$ in assprayed and to almost $82 \% \mathrm{wt}$ in annealed and grinded coating surface [5]. The NiCrBSi alloy is self-fluxing material, prone to improve its properties by the heat exposition. The precipitation of small boride particles, proved previously by XRD measurement [2], together with the increase of intersplat cohesion during annealing could lead to strengthening of the coating material. Finally, the microstructural changes of $\mathrm{Cr}_{3} \mathrm{C}_{2}-\mathrm{NiCr}$ coating, consisting from precipitation of small carbides from supersaturated $\mathrm{NiCr}$ matrix [2], negatively influenced the cohesion strength, but have low impact on the wear properties.

\section{Summary}

The mechanical and wear properties of as-sprayed and annealed coatings were measured by Vickers indentation method by ASTM G-65 and ASTM G-133. The high temperature exposure had low effect on the measured microhardness value, but influenced significantly the cohesive strength of the coatings. Nevertheless, the cohesive strength changes are not in agreement with the tendency of coatings' wear resistance. The incoherence in measured mechanical and wear properties showed that microhardness and cohesive strength are not the predicative in this context. The changes of wear resistance are more likely related to microstructure changes than to changes of interspalt cohesion strength. To measure the materials properties in the range of the splat, nanoindentation measurements should be rather used and will be performed in our next work.

\section{Acknowledgements}

The result was developed within the CENTEM project, reg. no. CZ.1.05/2.1.00/03.0088, project CENTEM PLUS (LO1402) and project no. SGS-2013-028.

\section{References}

[1] S. S. Chatha, H.S.Sidhu, B.S.Sidhu, Characterization and Corrosion-Erosion Behaviour of Carbide based Thermal Spray Coatings, Journal of Minerals Characterization \& Engineering Vol. 11 (2012) pp 569-586

[2] Š. Houdková, J. Černý, Z. Pala, P. Haušild, High temperature resistance of selected HVOF coatings, Key Engineering Materials Vol. 662 (2015) pp 111-114

[3] B. R. Lawn, M.V.Swain, Microfracture beneath point indentations in brittle solids, Journal of Materials Science 10 (1975) pp 113-122

[4] B. Bhushan, Introduction to Tribology, John Wiley \& Sons, New York,202

[5] Š. Houdková, E. Smazalová, Z. Pala, Effect of heat treatment on the microstructure and properties of HVOF sprayed Co-Cr-W coating, submitted to Journal of Thermal Spray Technology 